\title{
A study of evolution/suppression parameters of equatorial postsunset plasma instability
}

\author{
O. S. Oyekola \\ Department of Physics, Covenant University, Canaanland, Ota, Ogun State, Nigeria
}

Received: 27 June 2008 - Revised: 5 September 2008 - Accepted: 21 October 2008 - Published: 16 January 2009

\begin{abstract}
Evening equatorial pre-reversal vertical ion $\boldsymbol{E} \times \boldsymbol{B}$ $\operatorname{drift}\left(V_{Z P}\right)$ and the peak of the ionospheric $\mathrm{F} 2$ maximum altitude $\left(h m \mathrm{~F} 2{ }_{P}\right)$ of the postsunset equatorial F-layer, which are the essential parameters requisite for the generation or inhibition of postsunset bottomside equatorial irregularities were deduced from ionosonde observations made in the Africa region (Ouagadougou: $\sim 3^{\circ} \mathrm{N}$ dip latitude) between January 1987 and December 1990 for solar activity minimum, medium, and maxima $\left(\mathrm{F}_{10.7}=85,141,214\right.$, and 190, respectively) for quiet geomagnetic conditions. We investigate variations of evening equatorial pre-reversal drift and the corresponding altitude at four levels of solar activity. Our observations show strong variations with solar variability. Correlation analysis between these parameters indicates that the correlation coefficient value between $h m \mathrm{~F} 2{ }_{P}$ versus $V_{Z P}$ decreases considerably with increasing solar flux value. There seems to be no significant link between these parameters under high solar activity, especially for solar intensity $\mathrm{F}_{10.7}>200$ units. We conclude that meridional neutral wind in the F-region contributes substantially to the variations of the pre-reversal vertical plasma drifts enhancement and the peak $h m \mathrm{~F} 2$, particularly the electrodynamics during twilight high solar flux conditions.
\end{abstract}

Keywords. Ionosphere (Electric fields and currents; Equatorial ionosphere)

\section{Introduction and data base description}

The F-region vertical iron drift at the magnetic equator is a parameter of primary importance for all studies of equatorial ionosphere. In the early evening hours, a unique feature of the equatorial and low-latitude ionosphere is the pre-reversal

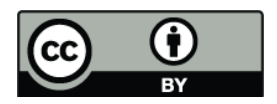

Correspondence to: O. S. Oyekola (ja_oyekola@yahoo.com) enhancement (PRE) in the vertical ion velocities that occurs shortly after local sunset, superimposed in the typical diurnal variation of daytime upward and nighttime downward drifts (Fesen et al., 2000). The phenomenon is mainly driven by eastward electric fields and can significantly change the height of ionosphere. The equatorial electric field and plasma drift vary with longitude at a given local time and affect the growth rate of the Raleigh-Taylor (RT) instability through the gravitational and electrodynamics drift terms and by controlling the electron gradient in the bottomside of the F-region after dusk (Farley et al., 1970; Ossakow, 1981; Abdu et al., 1982; Aarons, 1993; Fejer et al., 1999).

The height of the postsunset equatorial F-layer is another important parameter that controls the generation or inhibition of equatorial bottomside plasma instability (Jayachandran et al., 1993; Abdu, 2001). So far, the postsunset height studies have been limited to the height of the base of the Flayer, $h^{\prime} F$ resulting in a lack of data of the peak $h m \mathrm{~F} 2$. Already, it has become an established fact that the evening rapid rise of the F-layer, produced by a pre-reversal enhancement in the F-region ionization drift velocity, is closely linked in some way with the development of the equatorial spread $F$ (ESF) (Faley et al., 1970; Woodman, 1970). Furthermore, numerous studies regarding the effects of evening equatorial pre-reversal drifts in F-region instability have been presented (e.g. Fejer et al., 1999; Lee et al., 2005; Li et al., 2007; Whalen, 2001). Unfortunately, electrodynamic effects on the early evening ionosphere are infrequently studied in the African longitude sector. The understanding of ionosphere variability in regard to these key factors (evening prereversal enhancement and the corresponding peak height) have practical and scientific impacts.

Based on the ground-based ionosonde measurements, the analysis of seasonal and solar cycle variability in Fregion vertical ion drifts over Ouagadougou has been performed in our earlier study (Oyekola et al., 2007). By using ionosonde observations from Ouagadougou $\left(12.4^{\circ} \mathrm{N}\right.$,

Published by Copernicus Publications on behalf of the European Geosciences Union. 

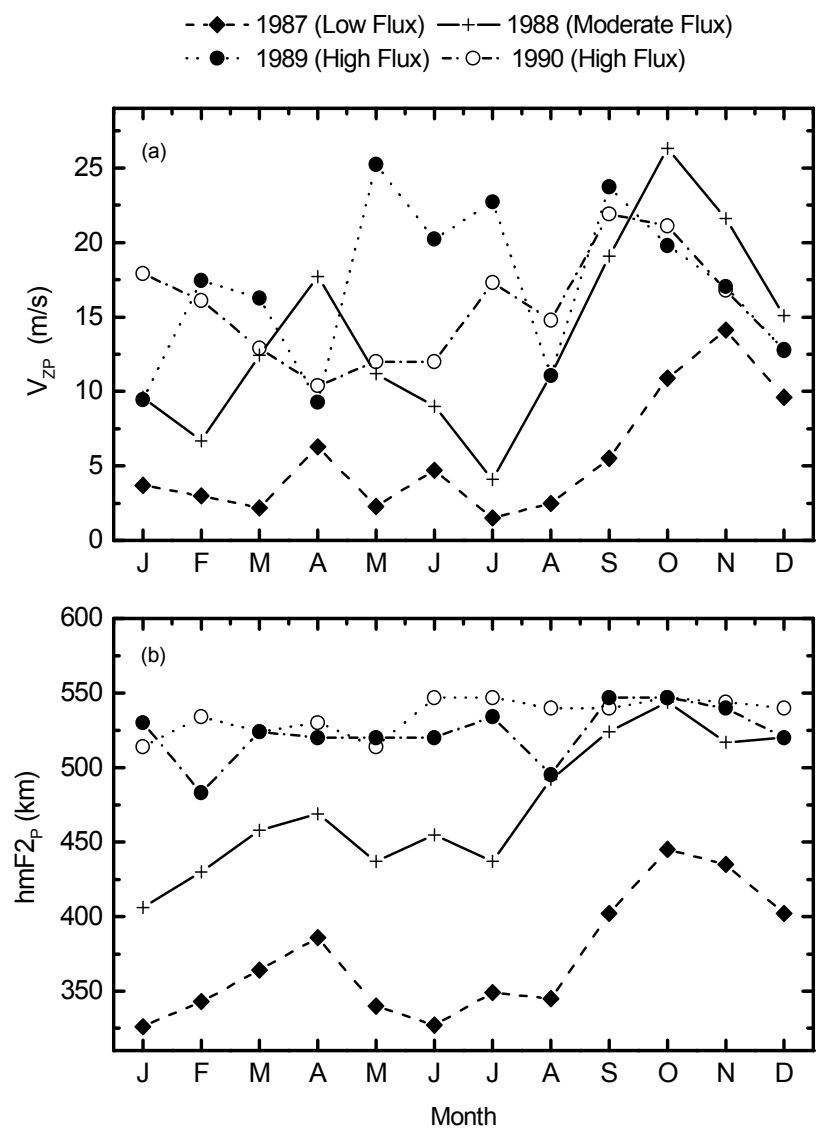

Fig. 1. Variation of (a) pre-reversal vertical ion drift $\left(V_{Z P}\right)$ and (b) the corresponding maximum $h m \mathrm{~F} 2{ }_{P}$ for four levels of solar activity.

$1.5^{\circ} \mathrm{W}$, dip latitude, $\sim 3^{\circ} \mathrm{N}$ ), we show the variation and the relationship between evening peak velocity $V_{Z P}$ and the corresponding evening peak altitude $h m \mathrm{~F} 2$ at various levels of solar activity. In addition, we show that at high solar activity period, meridional wind play a pivotal role in the variability of postsunset ionosphere. Details of the procedure for measuring F-region vertical drifts and the peak altitudes using ionosonde were fully described in earlier publications (Oyekola et al., 2007, 2008). Uncertainties in $V_{Z P}$ are in the range of $\sim( \pm 1-2 \mathrm{~m} / \mathrm{s})$, while that of $h m \mathrm{~F} 22_{P}$ varies between $\sim( \pm 4-13 \mathrm{~km})$.

\section{Results and discussion}

We present in Fig. 1a (top panel) the variation of evening equatorial pre-reversal vertical drift velocity for four different values of solar flux intensity $\mathrm{F}_{10.7}$ and in Fig. $1 \mathrm{~b}$ (bottom panel) the corresponding monthly averages of evening maximum $h m \mathrm{~F} 2$. The averaged monthly solar flux intensity $\mathrm{F}_{10.7}$ values were $85,141,214$, and 190 , respectively. The prereversal peak in vertical drifts is smaller at all months for the
Table 1. Regression parameters for Fig. 2.

\begin{tabular}{cccc}
\hline Year & $\begin{array}{c}\text { F10.7 (in } \\
\text { flux units) }\end{array}$ & Slope & $\begin{array}{c}\text { Regression } \\
\text { coefficients }\end{array}$ \\
\hline 1987 & 85 & 8.84 & 0.86 \\
1988 & 141 & 5.69 & 0.83 \\
1989 & 214 & 0.47 & 0.21 \\
1990 & 190 & 2.59 & 0.50 \\
\hline
\end{tabular}

lowest flux value. The moderate and high solar maxima show considerable fluctuations. Of particular important, the values of $V_{Z P}$ during moderate solar activity year $1988\left(\mathrm{~F}_{10.7}=141\right)$ are either roughly comparable or even higher than $V_{Z P}$ during the maximum solar activity year $1989\left(\mathrm{~F}_{10.7}=214\right)$ and $1990\left(\mathrm{~F}_{10.7}=190\right)$ in equinoxes (April and October) and December solstice (November and December) months. On average, the magnitude of the evening pre-reversal enhancement in vertical iron drift during 1987 (low), 1988 (medium), 1989 (high), and 1990 (high) is $5.5 \mathrm{~m} / \mathrm{s}, 13.7 \mathrm{~m} / \mathrm{s}, 17.1 \mathrm{~m} / \mathrm{s}$, and $15.5 \mathrm{~m} / \mathrm{s}$, in that order. Clearly, the values indicate solar activity dependence. A close look at Fig. 1b, one notes that the variability patterns show apparent solar activity dependence, but not as strong as in the PRE in the vertical ion drift. Again, peak $h m \mathrm{~F} 2$ are smaller in values during all the months for the lowest flux value. In addition, the trends during 1989 (high) and 1990 (high) are not significant compared to $V_{Z P}$ trends during the same periods. It is also noticeable that values of peak $h m \mathrm{~F} 2$ during the moderate solar activity year 1988 are approximately similar to maximum $h m \mathrm{~F} 2$ during 1989 and 1990 solar maxima periods. The overall average value of $h m F 2 p$ is $\sim 370 \mathrm{~km}, 470 \mathrm{~km}, \sim 535 \mathrm{~km}$, and $523 \mathrm{~km}$ for 1987, 1988, 1989, and 1990 periods, respectively. The average value of peak $h m \mathrm{~F} 2$ also indicates solar activity dependence.

Figure 2 presents the dependence of evening pre-reversal maximum in $\mathrm{F} 2$ peak height $h m \mathrm{~F} 2 \mathrm{p}$ on the postsunset vertical ion drifts for 1987, 1988, 1989, and 1990, respectively. Notice that the occurrence time of evening peak in the vertical drift is in the range 17:00-22:00 LT. Figure 2 shows four panels of plots along with the best-fit representing solar cycle minimum (left top), moderate (right top), maximum (bottom left), and maximum (bottom right) conditions. The best-fit parameters are put together as Table 1. It is interesting to see from the table that the slope connecting $h m \mathrm{~F} 2 \mathrm{p}$ and $V_{Z P}$ decrease considerably with the increasing phase of solar cycle. The correlation coefficient values, in the linear regression analysis is very good for the low and moderate solar activity year of 1987 and 1988, very poor during the high solar activity period of 1989 , but fair during the high solar flux year of 1990. Also, the regression coefficient values decrease drastically with an increase in the epoch of solar cycle. Furthermore, the data suggests that the parameters required initiating/suppressing postsunset bottomside 

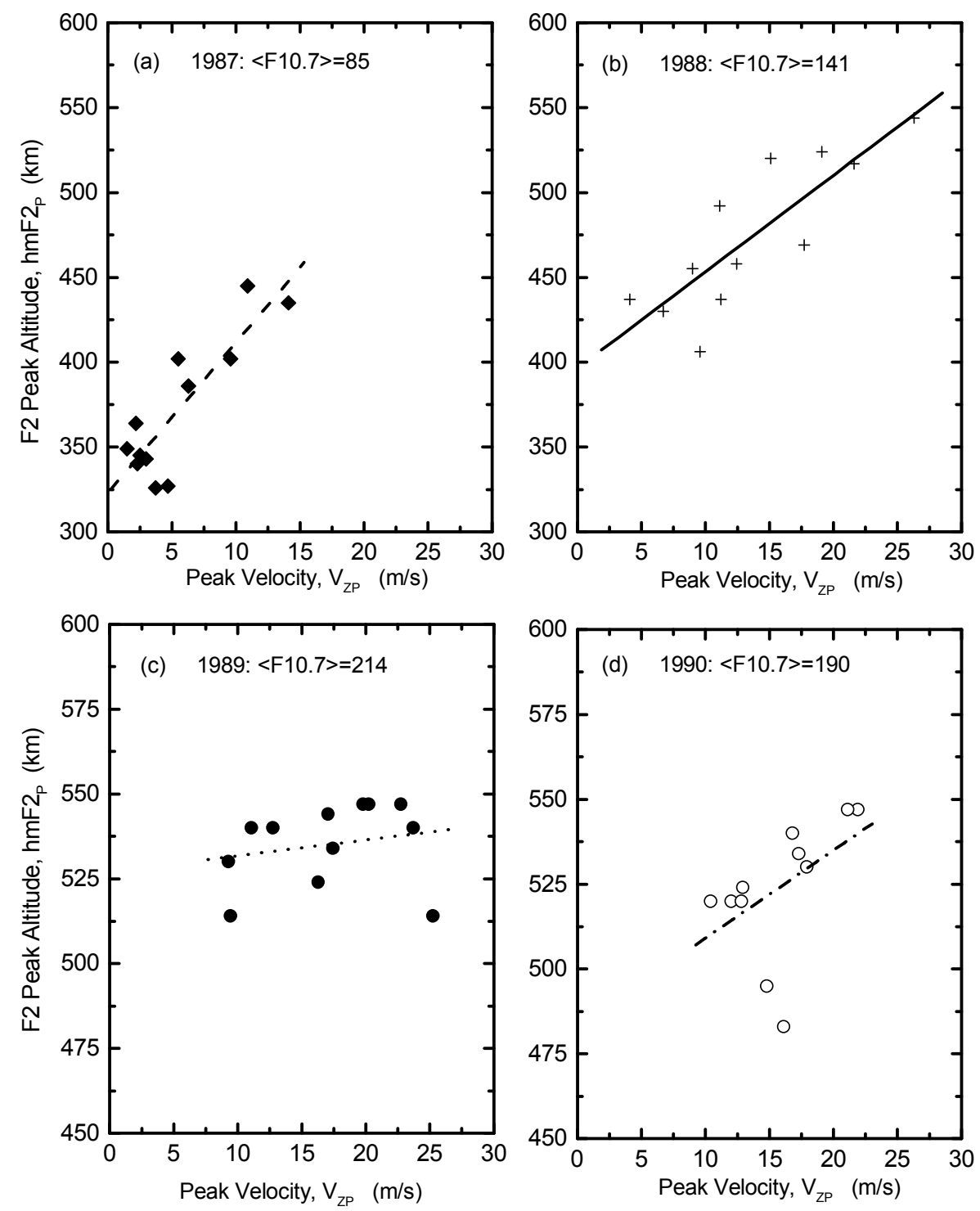

Fig. 2. Dependence of ionospheric peak $\mathrm{F} 2$ maximum height $\left(h m \mathrm{~F} 2{ }_{P}\right)$ on the evening pre-reversal enhancement in vertical ion drift. The average decimetric solar flux for each year is indicated on each panel.

irregularities exhibiting strong anti-correlation with the solar effect. It is important to stress that the peak velocity and maximum altitude relationship breaks down at higher solar activity suggesting that the pre-reversal enhancement width before reversal is important too. The lower solar activity relationships imply that the pre-reversal enhancement shape is fairly constant and the peak velocity is the main variable. Hence, we suspect that even when meaningful onset values $(\boldsymbol{E} \times \boldsymbol{B}$ in vertical ion drift or peak $h m \mathrm{~F} 2)$ needed to ignite postsunset plasma instability are met, plasma irregularities can still be inhibited during high solar activity periods. This result is in agreement with the report of Su et al. (2007) that used space-based (ROCSAT-1) observations to show anticorrelation between the solar activity effect and topside den- sity irregularity occurrence rate at longitude of bad alignment of magnetic field lines in a solstice season. It is observed that the magnitudes of the evening peak velocities are generally smaller, even the yearly average value is less than $20 \mathrm{~m} / \mathrm{s}$ (commonly reported threshold value of peak velocity necessary to trigger plasma instability) for each level of solar activity. Dabas et al. (1998, 2003, 2007), reported that day-to-day occurrence of scintillation at $4 \mathrm{GHz}$ up to $21^{\circ} \mathrm{N}$ magnetic latitudes is strongly dependent on the evening hour virtual height or $h^{\prime} F$ and the time rate of change of $h^{\prime} F$ values over the magnetic equator, and suggested that in the neighborhood of the magnetic equator, the threshold values of $\boldsymbol{E} \times \boldsymbol{B}$ (or $h^{\prime} F$ ) can be successfully used for the night-to-night prediction of scintillation occurrence. Horvath and Essex (2003) 


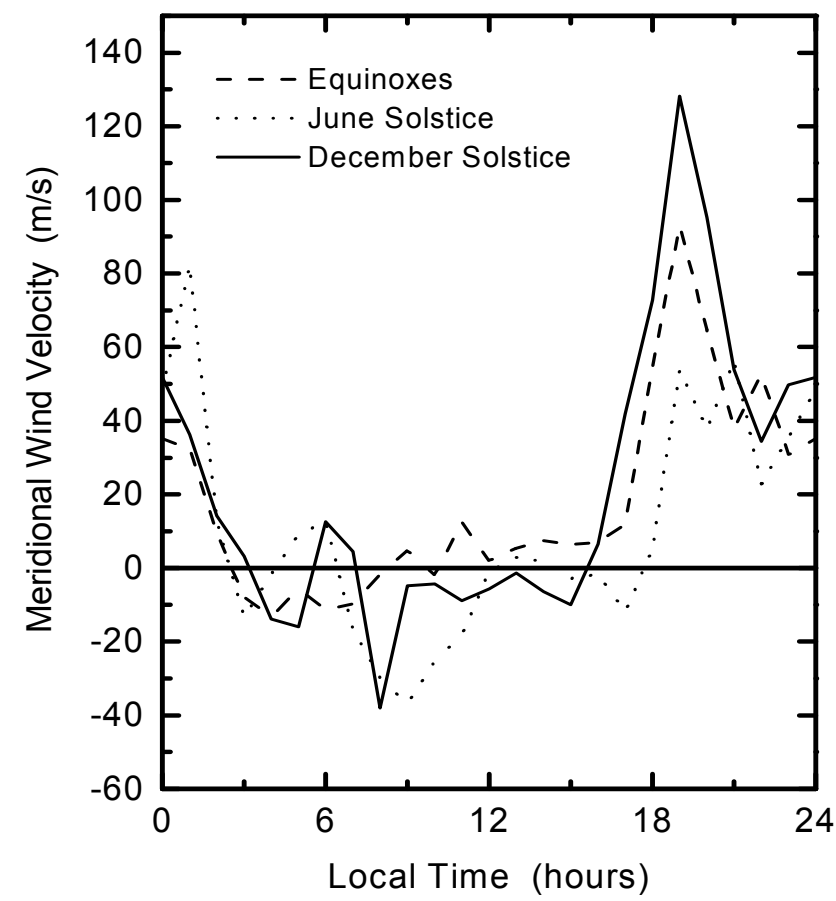

Fig. 3. Meridional neutral wind over Ouagadougou F-region ionosphere.

demonstrated the effects of the pre-reversal enhancement on the ground-based GPS TEC data at the equatorial latitudes in the Pacific longitude region.

It must be noted that Ouagadougou station is not located exactly at the magnetic equator, thus meridional neutral wind could play a vital role during high solar epoch. Therefore, an idea of how transequatorial wind intensity could affect the variation of evening prereversal enhancement and peak $h m \mathrm{~F} 2$ can be obtained from the data presented in Fig. 3, which shows the difference in the $h m \mathrm{~F} 2$ values over two magnetic conjugate point stations obtained from Ibadan $\left(3^{\circ} \mathrm{S}\right.$ dip latitude) and Ouagadougou ( $3^{\circ} \mathrm{N}$ dip latitude) during comparable solar and geophysical conditions. The $h m \mathrm{~F} 2$ values over the northern conjugate station is subtracted from that of the southern conjugate station $\left(h m \mathrm{~F} 2{ }_{\mathrm{IBA}}-h m \mathrm{~F} 2 \mathrm{OUA}\right)$. The resulting $\Delta(h \mathrm{mF})$ represents the direct measure of the transequatorial wind (Abdu et al., 2006). A positive (negative) value of $\Delta(h m \mathrm{~F} 2)$ represents the northward (southward) transequatorial wind. The data for the three different seasons are plotted in Fig. 3. We observe that northward transequatorial wind is considerably large within the December solstice, especially during the evening hours over Ouagadougou, moderate in equinoxes, and significantly weaker within the June solstice. This result is in agreement with the work presented by Mayer et al. (1979), who found the maximum around sunset in meridional wind during the equinoctial months of a high solar activity period. Thus, the large transequatorial winds (northward) in equinoxes and December solstice could be responsible for anti-solar correlation between the $h m \mathrm{~F} 2{ }_{P}$ and $V_{Z P}$ while at the same time quenching the instability growth in an otherwise unstable flux tube, thus maintains a stable ionosphere with perhaps no equatorial spread-F instability during equinoxes and solstice high solar flux conditions.

\section{Summary}

There exists large variation, particularly in the evening enhancement in the F-region peak velocity and the evening maximum $h m \mathrm{~F} 2$ measured over Ouagadougou for the four different values of solar decimetric flux. The F-region parameters $\left(V_{Z P}\right.$ and peak $\left.h m \mathrm{~F} 2\right)$ required to trigger the ESF instability exhibit strong anti-correlation with solar activity effect. We note that these parameters are poorly correlated during periods of high solar activity, particularly $\left(\mathrm{F}_{10.7}>200\right.$ units). In this way, the peak velocity and the corresponding altitude are confined to a narrow altitude range (see Fig. 2c) and, as a result, the ionosphere irregularity generation and evolution may possibly be weakened or inhibited. Lastly, two effects are found to contribute to the variation of evening F-region parameters, especially the electrodynamics; solar variability and the meridional neutral wind in the F-region.

Acknowledgements. We acknowledge the useful comments and suggestions made by the two referees on the draft of the paper and on the re-processing of Fig. 2.

Topical Editor M. Pinnock thanks V. Eccles and another anonymous referee for their help in evaluating this paper.

\section{References}

Aarons, J.: The longitudinal morphology of equatorial F-layer irregularities relevant to their occurrence, Space Sci. Rev., 63, 209-243, 1993.

Abdu, M. A.: Outstanding problems in the equatorial ionospherethermosphere elctrodynamics relevant to spread-F, J. Atmos. Solar-Terr. Phys., 63, 869-884, 2001.

Abdu, M. A., de Medeiros, R. T., and Sobral, J. H. A.: Equatorial spread $\mathrm{F}$ instability conditions as determined from ionogram, Geophys. Res. Lett., 9, 692-695, 1982.

Abdu, M. A., Batista, I. S., Reinisch, B. W., Sobral, J. H. A., and Carrasco, A. J.: Equatorial F-region evening vertical drift, and peak height, during southern winter months: A comparison of observational data with the IRI descriptions, Adv. Space Res., 37, 1007-1017, 2006.

Dabas, R. S., Lakshmi, D. R., and Reddy, B. M.: Day-to-day variability in the occurrence of equatorial and low-latitude scintillations in the Indian zone, Radio Sci., 33, 89-96, 1998.

Dabas, R. S., Sigh, L., Lakshmi, D. R., Subramanyam, P., Chopra, P., and Garg, S. C.: Evolution and dynamics of equatorial plasma bubbles: Relationships to $\boldsymbol{E} \times \boldsymbol{B}$ drift, postsunset total electron content enhancements, and equatorial electrojet strength, Radio Sci., 38, 1075, doi:10.1029/200RS002586, 2003. 
Dabas, R. S., Das, R. M., Sharma, K., Garg, S. C., Devasia, C. V., Subbarao, K. S. V., Niranjan, K., and Ramar Rao, P. V. S.: Equatorial and low latitude spread-F irregularity characteristics over the Indian region and their prediction possibilities, J. Atmos. Solar-Terr. Phys., 69, 685-696, 2007.

Farley, D. T., Balsley, B. B., Woodman, R. F., and McClure, J. P.: Equatorial spread F: Implication of VHF radar observations, J. Geophys. Res., 75, 7199-7216, 1970.

Fejer, B. G., Scherliess, L., and de Paula, E. R.: Effects of the vertical plasma drift velocity on the generation and evolution of equatorial spread F, J. Geophys. Res., 104, 19869-19869, 1999.

Fesen, C. G., Crowley, G., Roble, R. G., Richmond, A. D., and Fejer, B. G.: Simulation of the pre-reversal enhancement in the low-latitude vertical ion drifts, Geophys. Res. Lett., 27, 18611864, 2000.

Horvath, I. and Essex, E. A.: Vertical $\boldsymbol{E} \times \boldsymbol{B}$ drifts velocity variations and associated low- latitude ionospheric irregularities investigated with the TOPEX and GPS satellite data, Ann. Geophys., 21, 1017-1030, 2003,

http://www.ann-geophys.net/21/1017/2003/.

Jayachandran, B., Balan, N., Rao, P. B., Sastri, J. H., and Bailey, G. J.: HF Doppler and ionosonde observations on the onset conditions of equatorial spread F, J. Geophys. Res., 98, 13741-13750, 1993.

Lee, C. C., Liu, J.-Y., Reinisch, B. W., Chen, W.-S., and Chu, E. D.: The effects of the pre-reversal drift, the EIA asymmetry, and magnetic activity on the equatorial spread $F$ during solar maximum, Ann. Geophys., 23, 745-751, 2005,

http://www.ann-geophys.net/23/745/2005/.
Li, G., Ning, B., Liu, L., Ren, Z., Lei, J., and Su, S.-Y.: The correlation of longitudinal/seasonal variations of evening equatorial prereversal drift and of plasma bubbles, Ann. Geophys., 25, 25712578, 2007, http://www.ann-geophys.net/25/2571/2007/.

Mayer, H. G., Harris, I., Spencer, N. W., Hedin, A. E., Wharton, L. E., Parter, H. S., Walker, J. C. G., and Carson Jr., H. C.: Tides and midnight temperature anomaly in the thermosphere, Geophys. Res. Lett., 6, 447-450, 1979.

Ossakow, S. L.: Spread F theories - A review, J. Atmos. Terr. Phys., 43, 437-452, 1981.

Oyekola, O. S., Akin Ojo, Akinrimisi, J., and dePaula, E. R.: Seasonal and solar cycle variability in F-region vertical plasma drifts over Ouagadougou, J. Geophys. Res., 112, A12306, doi:10.1029/2007JA012560, 2007.

Oyekola, O. S., Ojo, A., and Akinrimisi, J.: A comparison of ground and satellite observations of F-region vertical velocity near the dip equator, Radio Sci., 43, RS1005, doi:10.1029/2007RS003699, 2008.

Su, S.-Y., Chao, C. K., Liu, C. H., and Ho, H. H.: Meridional wind effect on anti-solar activity correlation of equatorial density irregularity distribution, paper presented at International Symposium on Coupling Processes in the Equatorial Atmosphere (CPEA Symposium), held at Kyoto University Clock Tower Centennial Hall, Kyoto, Japan, 20-23 March 2007, pp. 1-36, 2007.

Whalen, J. A.: The equatorial anomaly: Its quantitative relation to equatorial bubbles, bottomside spread- $F$ and $\boldsymbol{E} \times \boldsymbol{B}$ drift velocity during a month at solar maximum, J. Geophys. Res., 106, 2912529132, 2001.

Woodman, R. F.: Vertical drift velocities and east-west electric fields at the magnetic equator, J. Geophys. Res., 75, 6249-6559, 1970. 